\section{SIMPLE SUPERCONDUCTIVITY}

\section{Superconductivity}

By A. W. B. Taylor. (The Wykeham Science Series for Schools and Universities.) Pp. xii +95. (Wykeham: London and Winchestor, March 1970.) $25 s$.

Trus is a qualitative account, written for the interested sixth former or first-year undergraduate. The author treats his audience fairly, presupposing mathematics only as far as simple calculus, and physics as far as Lenz's law and energy balance arguments. The book is very well illustrated and generally clearly written.

The first four chapters deal principally with the magnetic and resistive properties of typo I and type II superconductors. Flux quantization is introduced at an early stage, although the "quantum" nature of superconductivity is not overstressed. For my taste, there is perhaps too much on the intermediate state and too little on the mixed state. Applications (heat valves, bolometer, cryotron, Crowe cell, solenoids) are discussed; again I do not think the building blocks of the chimerical superconductive computer store deserve more space than solenoids.

In the fifth chapter, a qualitative account of the microscopic theory is given. The conceptual level is inevitably higher, and some readers may find this chapter too hard. Nevertheless, for those who persevere, the ways in which Cooper pair formation gives rise to the electromagnetic properties and a surface energy are well presented.

The index is adequate. Perhaps rightly, no references to the original literature are given, but it seems a pity that there is no list of books and articles for further reading.

In summary, within a short and readable book the author achieves his aims, and the book can be recom. mended.

D. R. TILLEX

\section{HOT PLASMAS}

The Physics of Hot Plasmas

Edited by B. J. Rye and J. C. Taylor. (Scottish Universities Summer School 1968.) Pp. xv +455 . (Oliver and Boyd: Edinburgh, May 1970.) 160s.

"THE main purposes of the summer school were to show how theory and experiment are linked and to highlight some of the current developments in the physics of hot plasmas." This is the motivation for this series of lectures, the notes of which are reproduced (sometimes in expanded form) in this volume. The locturers have succeeded in fulfilling these aims although perhaps rather better in the case of the latter.

The contributions on experimental techniques deal chiefly with diagnostics using lasers or optical methods. These form a valuable review of the subject but would have been even more useful if they were more correlated with some of the earlier theoretical papers. The section dealing with collisionless shocks, however, gives an excellent summary of the relationship between theory and exporiment in this field.

Current developments are covered extremely thoroughly and, indeed, it is doubtful if thore is any other unified source of some of this material. The chapters on kinetic theory progress from basic fundamentals through to some of the latest ideas on kinetic equations for a hot plasma. Instabilities are discussed exhaustively, including a treatment of non-linear effects using quantum mechanical ideas. The highly topical field of computation applied to the solution of some of the equations describing the plasma is also considered. Apart from these, there are short contributions on turbulence, laser produced plasmas and high density plasmas.

The level of the lectures was aimed at research students with, at least, one year of postgraduate experience in plasma physics. It is to be hoped that some of this material has been much expanded or the lectures must have been very hard going! The work is at the frontiers of the subject in many places and should certainly be available to all those whose work includes some reference to hot plasmas. In fact, the bias is understandably towards controlled fusion research, but the ideas presented should be of value to others beyond this field. In summary, the cditors are to be congratulated on producing a coherent and valuable reference work.

D. A. DUNNETT

\section{ORGANIC GEOCHEMISTRY}

\section{Organic Geochemistry}

Methods and Results. Edited by G. Eglinton and M. T. J. Murphy. Pp. xxiv + 828. (Longman: London; SpringerVerlag: Berlin, Heidelberg and New York, May 1970.) $360 s$.

For many years the subject matter encompassed by this book was largely limited by investigations on coal and petroleum. Since Berger's Organic Geochemistry in 1962 the subject has developed to bring together various aspects of chemistry, geology and biology. Although the approach is that of the organic chemist rather than the geologist, the book provides an overall view of these fields. Certain topics have been dealt with by different contributors and, although this necessarily causes some overlap between chapters, it is often wolcomed.

The contributions by thirty-seven scientists divide more or less equally into four groups: analytical methods, geological processes and principles, abundance of specific classes of organic compounds and specific topies. Ordering of subject matter within these groups could be improved. Chapters on analytical methods explain tools and methods used to characterize organic compounds and include two detailed chapters on high resolution mass spectroscopy and gas chromatography. They are quite digestible to the nonchemist. The geological chapters as applied to sediments and fossils are somewhat elementary, with excessive overlap. It is questionable whether chapters of this type have a place in a book of this sort. It is unfortunate that the subject of organic matter in sediments exists only in outline, because its author, D. H. Welte, suffered a prolonged illness during the book's development. Abundance and microbiological breakdown of organic compounds in recent sediments is, however, excellently treated in other chapters.

Eleven chapters on the abundance and behaviour of specific organic compounds are grouped together according to their biochemical development. These include articles on hydrocarbons, fatty acids, alcohols, carbohydrates, terpenoids, carotenoids, proteins, peptides, amino-acids, porphyrins and humic acids. Many of these articles, besides reviewing the subject, also reveal important advances in understanding the fate of these substances during geological or biological procosses. Chapters concerned with specific organic substances or special goological situations include, besides the accounts of coal and petroleum, a number of well written articles on organic complexes in clays, minerals and shells.

Aside from the carping, the book is excellently produced, with very fow misprints. The standard of the individual articles is generally very high and covers most of the literature to 1967-68 with more recent work in addenda. I $t$ is a most important and timely addition to the literature of this fast developing subject. Besides being an essential addition to any geological or chemical library its expense, dare I say it, should not restrict it from being bought by many specialized workers.

The oditors should be congratulated on producing such an excellent book: it is a "must". N. B. Price 